\title{
The Sound of Lost Homes - Introducing the COVER Model - Theoretical Framework and Practical Insight into Music Therapy With Refugees and Asylum Seekers
}

\author{
Tina Mallon ${ }^{1 *}$, Monika Hoog Antink ${ }^{2}$ \\ 1 Department of Primary Medical Care, University Medical Centre Hamburg-Eppendorf, Hamburg, Germany \\ 2 Musiktherapie-Initiative e.V., Hamburg, Germany \\ *t.mallon@uke.de
}

Received: 16 June 2020 Accepted: 11 May 2021 Published: 1 July 2021

Editor: Melody Schwantes Reviewers: Nicky Haire, Bernard Muriithi

\begin{abstract}
Due to the difficult situation of refugees, working with this group is challenging. Yet, music therapy is a suitable method for early therapeutic intervention. The authors introduce the context-sensitive classification model for music therapeutic interventions with refugees-COVER model- which is based on practical music therapeutic experiences using a trauma-informed approach with refugees in Germany. The COVER model can serve as a guideline for music therapists who work with refugees in insecure circumstances. The COVER model applies music therapeutic interventions to the natural living environment of refugees and allows for early interventions which may be a crucial benefit to the psychological health of refugees and music therapists working in this area.
\end{abstract}

Keywords: refugees, asylum seekers, early therapeutic intervention, COVER model, natural living environment, trauma-informed approach

\section{Introduction}

Literature and research on music therapy with refugees and asylum seekers has been mainly focusing on the clinical settings, music therapeutic methodology and interventions which start rather late during the process of arrival (Bensimon et al., 2008; Lauzon, 2019; Orth, 2005; Zharinova-Sanderson, 2004). Yet, recent studies show that refugees and asylum seekers are under increased risk of developing common psychiatric disorders, such as depression, anxiety and post-traumatic stress disorder (PTSD), as well as an increase in disabling symptoms of psychosocial stress due to their dramatic experiences before, during, and after the flight (Gonsalves, 1992; Hassan et al., 2016; Hebebrand et al., 2016; Laban et al., 2004; Marquardt et al., 2016; Metzner et al., 2016). Additionally, difficult living conditions can have a negative impact on the ability of refugees to cope with their traumatic experience (Carswell et al., 2011). 
Particularly war-affected refugee children and unaccompanied asylum-seeking adolescents are under risk of developing mental health problems, making them more vulnerable to the exposure of community violence, domestic violence, and physical and emotional abuse even past the resettlement period (Betancourt et al., 2012; Guruge \& Butt, 2015; McGregor et al., 2015).

Therefore, an early support for mental health care needs and early therapeutic interventions seems necessary. Yet, therapy onset faces a lot of challenges such as a lack of therapists, language barriers, lack of trained interpreters, lack of cover for therapy costs or reservations against any form of therapy. Music therapy can provide a culturally-centred, low-entry threshold approach in the treatment of mentally affected refugees from an early stage of arrival onwards (Abdulbaki \& Berger, 2020).

To the best of our knowledge, no concept on early interventions in different settings with music therapy for refugees and asylum seekers has been made public. However, a number of music therapeutic interventions with refugees such as singing, song writing, instrument play, improvisation, lyric analysis, music listening, music imagery and music-based relaxation have been proven ideal for this group (Lauzon, 2019; Orth, 2004).

In Germany, numbers of asylum seekers increased from 202,834 in 2014 up to 745,545 in 2016 due to the ongoing conflicts in Syria, Iraq, Afghanistan and Eritrea, creating a high demand for health care, social and psychological support among those seeking shelter (Mediendienst, 2020).

Therefore, the Musiktherapie-Initiative e.V., a German non-profit association of trained music therapists located in Hamburg, started to provide music therapy for refugees and asylum seekers in refugee reception centres and follow-on camps. The experiences gained from 2013 to 2018 led to the development of the "COVER Model - COntext-sensitive classification model for music therapeutic interVEntions with Refugees" which we would like to introduce to the music therapeutic community as a tool for music therapeutic interventions based on the natural living environments of refugees.

\section{The COVER Model}

The context-sensitive classification model for music therapeutic interventions with refugees-COVER model is a first attempt to classify the music therapeutic experience with refugees using the refugee's natural living environment within the given setting, in our case the refugee reception centres and follow-on camps. Rather than using external therapy settings, the music therapy sessions were directly provided at the camps. Depending on the given setting different kinds of music therapy sessions have been applied: open group sessions (OGS) in refugee reception centres, small group sessions (SGS) in follow-on camps, and individual therapy sessions (ITS) in outpatient therapy. It is important to note that the model is not based on a specific music therapeutic approach (e.g., behavioural, psychodynamic, or psychoanalytic). Yet, our therapeutic goals such as nurturing of personal strength; coping skills; and mobilizing social, cultural and material resources can be related to a community music therapy approach (Stige, 2015). Rather, the Musiktherapie-Initiative e.V. applied a context-sensitive, trauma-informed approach meaning to be attentive to the multilevel impacts of trauma, recognizing signs and symptoms of trauma, finding a fitting response, and efforts to prevent re-traumatization (Champine et al., 2019; Rolvsjord, 2015).

Additionally, consideration of the multi-cultural aspects in therapy as well as the music therapist's reflection and evaluation of the instruments and music used in music therapy seemed necessary in order to offer the participants ways to express themselves (Comte, 2016). Multicultural awareness can serve as a key when working with people from multiple cultural backgrounds (Hadley \& Norris, 2016).

\section{Method}

As every setting presented its own challenges for the music therapists, the participants also presented the therapists with different needs depending on the setting. Therefore, 


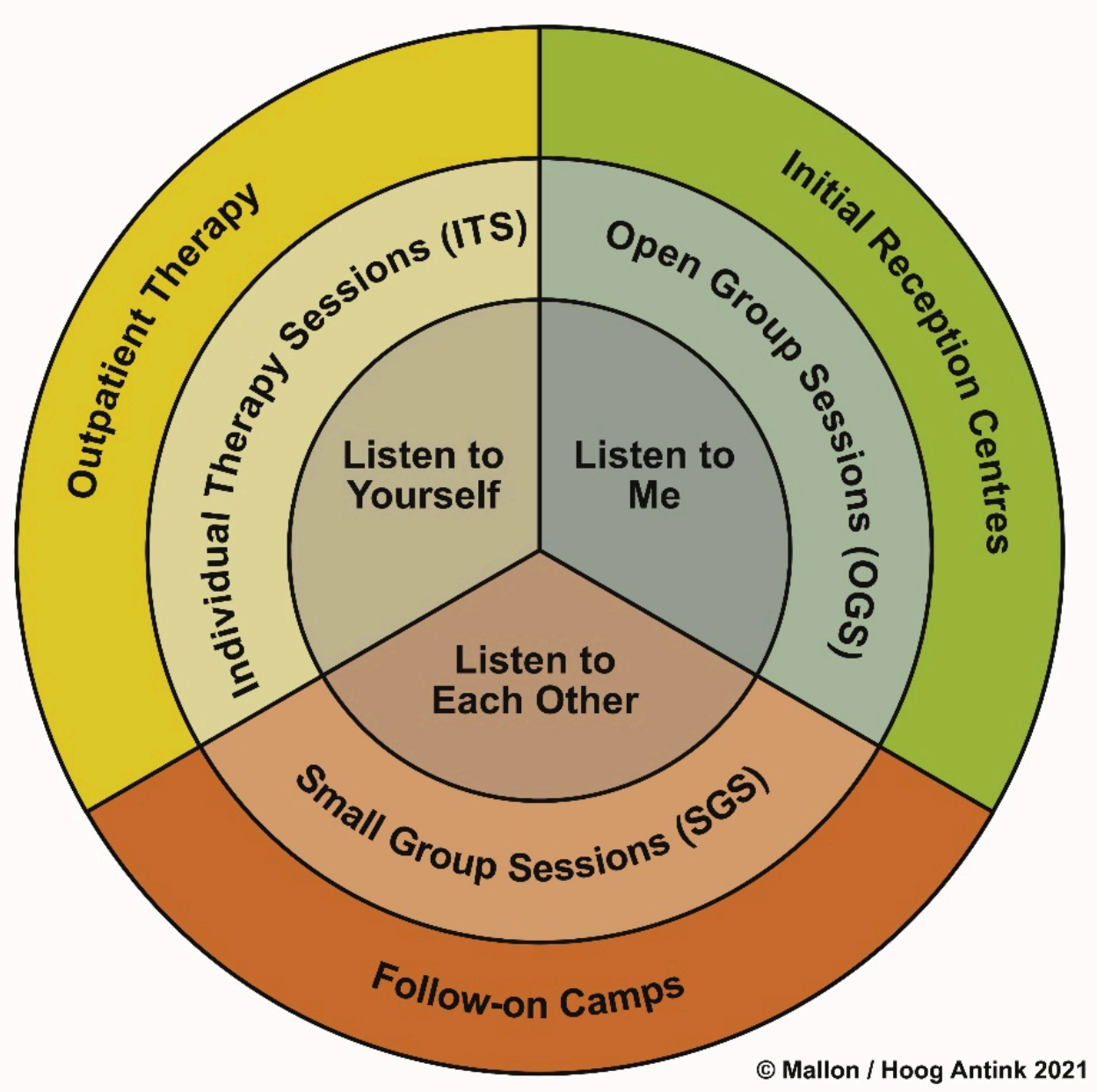

Figure 1

The COVER Model

each of the three settings was labelled based on what was perceived and observed as the most important task for the music therapist and needs of the participants working in the setting (inner circle).

Open group sessions were labelled "Listen to me" for the 'need to be seen' seemed to be the main topic within the refugee reception centres. The task of the music therapist was to ensure that each participant was heard and given the same attention. Feelings of sadness, hopelessness, hopefulness, expectations, frustrations and being lost were perceived strongly by the music therapist. Coping with the large amounts of mixed feelings experienced by the music therapist was a challenge.

The label "Listen to each other" was given to small group sessions which were mainly used in follow-on camps. The setting allowed for a smaller group size and more privacy. The focus could turn more towards the present topics such as language barriers, homesickness, worries about loved ones etc. Working in this setting with participants from similar background allowed the groups to "Listen to each other," to give everyone their own space and time to share experiences.

Individual therapy sessions were labelled with "Listen to yourself" and normally applied within an outpatient setting. The ITS allowed for a more in-depth therapeutic approach and provided enough security to address conflict-related topics. The sessions took place weekly and provided a secure therapeutic relationship. Moreover, the safety of this setting helped to prevent re-traumatization (Champine et al., 2019) and to enable the patient to focus on their own symptoms, personal resources and needs. 
Table 1

Overview of the music therapy sessions

\begin{tabular}{|c|c|c|c|}
\hline & $\begin{array}{l}\text { Open Group Sessions } \\
\text { (OGS) }\end{array}$ & $\begin{array}{l}\text { Small Group Sessions } \\
\text { (SGS) }\end{array}$ & $\begin{array}{l}\text { Individual Therapy Sessions } \\
\text { (ITS) }\end{array}$ \\
\hline Label & Listen to me & Listen to each other & Listen to yourself \\
\hline Setting & Initial reception centre & Follow-on camps & $\begin{array}{l}\text { Outpatient therapy setting } \\
\text { outside camps; schools }\end{array}$ \\
\hline Group form & Open and improvised & $\begin{array}{l}\text { Open group with more } \\
\text { consistent members }\end{array}$ & One-on-one \\
\hline $\begin{array}{l}\text { Number of } \\
\text { participants }\end{array}$ & $2-45$ & 12 & 1 \\
\hline Duration & $60-120$ minutes & 60 minutes & 50 minutes \\
\hline Participants & $\begin{array}{l}\text { Mixed; mainly young men and } \\
\text { children, some women }\end{array}$ & $\begin{array}{l}\text { Men (with similar cultural } \\
\text { background) or children }\end{array}$ & Individual \\
\hline $\begin{array}{l}\text { Acquisition } \\
\text { of } \\
\text { participants }\end{array}$ & $\begin{array}{l}\text { Written announcements in dif- } \\
\text { ferent languages, verbal invita- } \\
\text { tion by music therapists }\end{array}$ & $\begin{array}{l}\text { Written and verbal invita- } \\
\text { tion by social workers and } \\
\text { music therapists }\end{array}$ & $\begin{array}{l}\text { Consultations with school } \\
\text { teacher/doctor/psychiatrist }\end{array}$ \\
\hline Concept & $\begin{array}{l}\text { Instrument building workshops } \\
\text { Drum sessions } \\
\text { Singing groups }\end{array}$ & $\begin{array}{l}\text { Low entry threshold mu- } \\
\text { sic therapy group }\end{array}$ & $\begin{array}{l}\text { Psychodynamic music thera- } \\
\text { py (with focus on trauma- } \\
\text { based music therapy) }\end{array}$ \\
\hline $\begin{array}{l}\text { Role of the } \\
\text { music } \\
\text { therapist }\end{array}$ & Facilitator/guide & Guide/therapist & (psycho-)therapist \\
\hline $\begin{array}{c}\text { Goal / } \\
\text { intervention }\end{array}$ & $\begin{array}{l}\text { Empowerment } \\
\text { Discover resources } \\
\text { Contact to other camp members } \\
\text { Space for individuality }\end{array}$ & $\begin{array}{l}\text { Supporting } \\
\text { Grounding } \\
\text { Mirroring individual } \\
\text { needs } \\
\text { Exploration }\end{array}$ & $\begin{array}{l}\text { Being in the 'here and now' } \\
\text { Support resettlement } \\
\text { process }\end{array}$ \\
\hline Music & $\begin{array}{l}\text { Circle songs } \\
\text { Canon } \\
\text { Pop songs } \\
\text { Songs taught by the participants } \\
\text { Simple rhythms }\end{array}$ & $\begin{array}{l}\text { Songs from the country of } \\
\text { origin } \\
\text { Producing own music } \\
\text { Instrumental roll plays } \\
\text { Singing } \\
\text { More complex rhythms }\end{array}$ & $\begin{array}{l}\text { Connected to the individ- } \\
\text { ual's emotional state }\end{array}$ \\
\hline Instruments & $\begin{array}{l}\text { Small instruments } \\
\text { Body percussion } \\
\text { Dancing }\end{array}$ & $\begin{array}{l}\text { Small instruments } \\
\text { Drums } \\
\text { Body percussion }\end{array}$ & $\begin{array}{l}\text { All general music therapy in- } \\
\text { struments }\end{array}$ \\
\hline
\end{tabular}

\section{The Settings and Sessions in Detail}

In the following section a short description for each kind of session, its aim and structure, music and special aspects, as well as case examples are provided. Table 1 also gives an overview.

\section{Open Group Sessions (OGS) - Working in initial reception centre settings}

\section{Aim and Structure of the Setting}

OGS are defined as either a one-time open group or repeating open group session once a week. This included one-day instrument building workshops, weekly open drum ses- 
sions and fortnightly open circle singing sessions. The sessions were improvised due to the number of participants, the group dynamic, and the individual resources and needs. Most of the participants were men. Working in this setting was characterized by freedom to come and go. The groups were half-open (due to newcomers and others leaving the camp) and needed great flexibility. The place and time for the group could vary also due to external influences. The number of people attending OGS varied immensely between 2 to 45. Empowering participants, discovering one's own resources, establishing contact among the camp members and allowing space for individuality were the main interventions. To provide more structure to the session, songs were repeated often. Participants were welcome to introduce songs, rhythms or dances of their own to encourage musical participation and social inclusion (Stige, 2015).

\section{Music and Special Aspects}

In this particular setting and during the sessions, music therapists were challenged to incorporate the multicultural backgrounds of the participants. Yet, the multinational group, however, shared knowledge of the same songs like Shakira's "Waka Waka" due to the soccer championship or "We will rock you." As a result, these songs were sung during almost every session regardless of one's nationality, gender and age. In the singing group the repertoire included pop songs, African canons, simple German folk songs or songs from the home countries (e.g., in Farsi or Arabic). The African canons included only up to four words and were learned by the whole group as something new together.

Using songs in the participant's language led to self-empowerment and change in the group dynamics as well as between therapists and participants. Teaching the right pronunciation caused many moments of joy and allowed the 'teacher' to stand out. The songs were accompanied by small percussion instruments and body music (e.g., hand claps and stamping of feet) and movements. For some participants it was very difficult to hold a rhythm with their body or coordinate movements. Therefore, the rhythms were kept very simple.

The participants took turns in singing and improvising a verse with great pride in their performance. Participants wanted to distinguish themselves in some way either by showing off musical skills, leadership or simply through the volume of playing. We interpreted this behaviour as a strong need to be recognized as more than just a refugee.

Case Example

During all the sessions the participants started dancing freely. Short dance competitions occurred, where two or three persons danced in the middle of the circle and the rest could applaud or simply watch and be part of the event. Ahmed1, a young man who watched from the background and was quite silent, used the competition to get active. He enjoyed being seen and showed passion to use his body. The same phenomenon occurred when the whole group was split into smaller subgroups to sing a canon or a circle song which brought a lot of joy to the participants.

\section{Small Group Sessions (SGS) - Working in Follow-on Camp Settings}

\section{Aim and Structure of the Setting}

SGS are defined as a small, more consistent, weekly group sessions with 12 participants. Participants had a similar cultural background and stayed for a full session. The sessions were clearly structured and took place in a room within the premises.

Supporting, grounding and mirroring were the main interventions during the sessions. The participants were supported to choose instruments and communicate their wishes and needs. Within the group the music and the safety provided through the setting allowed participants to give more insight into their emotional state. 


\section{Music and Special Aspects}

Sharing the same cultural and religious background seemed to speed up the group formation process and helped the participants familiarize with each other to the new or unknown form of music therapy. It provided music in a 'natural way,' meaning that participants quickly joined when one participant started singing a song from the country of origin. The growing sense of familiarity presented the opportunity for the participants to show some of their emotions. In these cases, the music functioned as a 'door opener,' meaning the music empowered therapists and clients to bridge the cultural gap and allowed them to connect with one another. During the sessions, the participants wanted to produce a "nice" piece of music, e.g., without dissonances. In many cases, rhythms were complex, and polyphony and quarter tones were common. On the other hand, moments of silence were greatly avoided and considered unbearable by many of the group's participants.

\section{Case Example}

A group of 12 men with Syrian and Afghan background caught interest in the music therapy project which had been running on a weekly basis in the camp and was mainly addressing children. In order to start a new group with the male adults, the children had to understand that the new group was not an addition to their running group. Yet, the children would not allow the men into 'their' space (the music room) and interrupted the process constantly by entering the room and protesting loudly. In addition, the men contributed great effort to make the room their own for the time of the group by setting it up with chairs, instruments and organizing an alternative activity for the children during the time of the group. The initiative and determination of the participants to engage was validated and started an instant group process which allowed the participants to share current and past experiences on a deeper level.

\section{Individual Therapy Sessions (ITS) - Working in Individual Outpatient Therapy} Settings

\section{Aim and Structure of the Setting}

ITS $^{2}$ are permanent, weekly one-on-one settings e.g., in an outpatient setting outside the refugee's home or in schools. The ITS allowed for a deeper, dynamic approach within the complex situation of the participant. Each session lasted 50 minutes. Focus lay in working in the 'here and now' and supporting the resettlement process.

\section{Music and Special Aspects}

As is the case in any individual therapy, there can be no general description of its content or music. However, in many cases, the music could be described as chaotic at the start and contained a large variety of emotions, which also evoked strong emotions within the therapists. Yet, expressing the inner emotional state was often difficult due to the lack of a common language. It was therefore indispensable for the music therapist to carefully intervene and guide the client through the sessions and to contain the situation.

Also, talking about one's problem with a trained therapist of any kind was a new experience to many participants. Certain fears, e.g., risking the chances for asylum by giving away personal details, fear for family left in the home country, or general mistrust at the beginning towards the therapist or method, made the process difficult.

During the music therapy sessions participants seemed to prefer instruments from their cultural background. We observed that string instruments were often used by Syrian, Afghan, Iranian or Iraqi participants, any kind of drums by participants from Eritrea or Somalia, and tabour or goblet drum by Syrian or Afghan participants. These instruments could represent a familiarity and provide a connection between the new and old culture. A tendency for regression was observed while participants played these instruments, meaning, as a defence mechanism, the person temporarily went into 
an earlier developmental state in order to cope with psychological stress which may be brought up by the familiar sounds of the instruments (Scheiby, 2015). The ITS setting aimed to create a safe space which allowed the participants to address more difficult topics in order to help overcome painful experiences during the flight and camp situation.

\section{Case Example}

Ali is a 9-year-old boy from Eritrea who fled across the Mediterranean with his family. He receives music therapy for 3 months. He does not talk much to the therapist and is easily scared. The music therapist gained his trust slowly. In the music therapy room there is a tipi, serving as a safe and hiding place within the room. The tipi has two small windows.

A repeating scene could be described as follows: Ali chooses the djembe at the beginning of the session and drums loud and furiously on the djembe. The music therapist not being allowed to play the same instrument, chooses the piano in order to be loud enough and to signal Ali he is not alone in the music as well as offering a structure and a contrast. The music therapist has to keep her distance. Ali needs space. Close by him there is the hand puppet lion which often comforts him. After a loud an intense drumming Ali stops, places the lion in front of the tipi, disappears inside it and closes the 'door' behind him. The music therapist, still at the piano, improvises the music according to the situation. The impulsive, loud music from the beginning of the session slowly turns into a quiet and comforting, melodic sound. Ali's only sentence in this session follows a few minutes after he disappeared in the tipi: "I want to sleep". The music therapist then starts to play and hum a German lullaby softly on the piano.

\section{Discussion}

The COVER model is a first attempt to describe music therapy with refugees based on the natural living environment such as refugee reception centres with large numbers of people, follow-on camps with generally fewer people, and an outpatient setting. As we experienced a distinct difference of feasible interventions due to rules and regulations in each setting, the applied music therapy concept had to change according to the natural living environment. Hence, our model uses the setting in which music therapy takes place as its initial point and uses different interventions in each session according to what each setting offers.

As refugees go through different stages in the resettlement process over time, the therapeutic interventions, as well as the therapist's role, the refugees tasks and treatment change by the length of time since arrival in the new country (Gonsalves, 1992). Gonsalves describes five stages of arrival in relation to therapeutic interventions. In stage one, ("Early Arrival") orientation, diminishing confusion and preventive strategies with culturally acceptable interventions are primary. Bridging the transition from the homeland to the host country is the declared goal. It also points out that natural settings in which the refugees gather should be used rather than external surroundings, which is in line with our concept and approach to provide music therapy at the reception centres and camps directly.

The music therapeutic interventions applied under "Listen to Each other" also incorporate many of Gonsalves' aspects for stage two ("Destabilization") and three ("Exploration and Re-stabilization"), which describe the time of confrontation with the new culture as well as a mixture of feelings, e.g., anger, sadness, loneliness, homesickness, isolation and anxiety about failures. Gonsalves points out that connections to other refugees are crucial for maintaining feelings of continuity with the past, and an openness towards the new culture is needed to master this phase. In SGS, a closer connection among the participants was evident. The smaller group sessions provided safety to the participants and allowed to create stronger bonds between the group members and the music therapists. Also, we used the positive influence of music in reducing stress levels and anxiety (Pelletier, 2004; Walworth, 2003) as well as PTSD symptoms during group music therapy sessions (Bensimon et al., 2008). 
In our model, the label "Listen to yourself" generally refers to the time after the refugee camps or follow-on camps, when a safer environment is established and an understanding of the new culture's norms and values starts to emerge. Confrontations with the past and present were common during that stage and refugee patients who needed more in-depth treatment to overcome their past had the chance to integrate their experiences and address inner conflicts within this individual outpatient therapy setting.

\section{Limitations}

The model is based on observations during the music therapy sessions portraying only a certain extent of the challenges and difficulties experienced by the participating refugees and music therapists.

Also, most of the group's participants were male or children. Women did not join the groups as regularly and no solely female group could be established. Therefore, our observations apply mainly to male participants and children. Cultural boundaries, social roles and thresholds may need to be investigated further in order to apply the model to women.

\section{Conclusion}

There can be no doubt that many refugees are in need of therapeutic support. Access to mental health services is often difficult and community-based and preventive interventions with family or peers seem most advisable (Betancourt et al., 2010, 2012). An early intervention after traumatic events is crucial in order to prevent a chronification of trauma (Oral et al., 2016). Even though not every refugee is affected by trauma, providing or adapting the setting according to the trauma-informed approach seems recommendable. Safety in the process and structures for orientation, e.g., at the start and the end of each music therapy session help the participants. Creating a safe therapeutic environment to allow the participants to express their personal thoughts and feeling seems crucial.

The limited access to mental health facilities, language barriers and the lack of available interpreters call for the use of creative arts therapies such as music therapy. Music therapy is preferable for interventions when communication through spoken language is unavailable (Sutton \& De Backer, 2009). Music can be considered a universal language concerning its function as a communicator for emotions and personal expressions. Especially the social functions of music such as contact and empathy with and for others, increase of well-being, cooperation, synchronization and increased social cohesion of a group define music therapy as a perfect method of early therapeutic intervention (Koelsch, 2015). The connecting elements of music help to create an atmosphere of familiarity and trust even in unfamiliar surroundings and allow for emotional expression and regulation through active music making. Using our COVER model and applying the music therapy interventions to the natural living environment of the refugees allows for an early intervention and may be a crucial benefit to the psychological health of refugees.

\section{About the Authors}

Tina Mallon, music therapist M.A. has studied psychology and musical education in Erfurt and music therapy in Hamburg, Germany. She is one of the founding members of the Musiktherapie-Initiative e.V. Since 2013, she has been working with refugees and traumatized children. She is also a research scientist working at the Department of Primary Care at the University Hospital Hamburg-Eppendorf.

Monika T. Hoog Antink studied creative therapy with special focus in music in $\mathrm{Ni}$ jmegen, The Netherlands, followed by a master's degree in music therapy in Hamburg, Germany. She works with children with severe to profound disabilities, in palliative care and dementia care. Currently, she is involved in a research project on how to de- 
velop music therapeutic research methods for children with severe to profound disabilities.

\section{Notes}

1. All names and other personal characteristics of the patients described herein have been altered in order to protect their identities.

2. ITS are part of the model that have not yet been accomplished through the work of the Musiktherapie-Initiative e.V. but through work in clinical or ambulatory music therapy settings.

\section{References}

Abdulbaki, H., \& Berger, J. (2020). Using culture-specific music therapy to manage the therapy deficit of post-traumatic stress disorder and associated mental health conditions in Syrian refugee host environments. Approaches: An Interdisciplinary Journal of Music Therapy, 12(2). http://approaches.gr/wp-content/uploads/2020/12/

4-Approaches-12-2-2020-a20190530-abdulbaki.pdf

Bensimon, M., Amir, D., \& Wolf, Y. (2008). Drumming through trauma: Music therapy with post-traumatic soldiers. The Arts in Psychotherapy, 35(1), 34-48. https://doi.org/10.1016/ j.aip.2007.09.002

Betancourt, T. S., Brennan, R. T., Rubin-Smith, J., Fitzmaurice, G. M., \& Gilman, S. E. (2010). Sierra Leone's former child soldiers: A longitudinal study of risk, protective factors, and mental health. Journal of the American Academy of Child \& Adolescent Psychiatry, 49(6), 606-615. https://doi.org/10.1016/j.jaac.2010.03.008

Betancourt, T. S., Newnham, E. A., Layne, C. M., Kim, S., Steinberg, A. M., Ellis, H., \& Birman, D. (2012). Trauma history and psychopathology in war-affected refugee children referred for trauma-related mental health services in the united states: Trauma and psychopathology of refugee children. Journal of Traumatic Stress, 25(6), 682-690. https://doi.org/10.1002/ jts. 21749

Carswell, K., Blackburn, P., \& Barker, C. (2011). The relationship between trauma, postmigration problems and the psychological well-being of refugees and asylum seekers. International Journal of Social Psychiatry, 57(2), 107-119. https://doi.org/10.1177/ 0020764009105699

Champine, R. B., Lang, J. M., Nelson, A. M., Hanson, R. F., \& Tebes, J. K. (2019). Systems measures of a trauma-informed approach: A systematic review. American Journal of Community Psychology, 64(3-4), 418-437. https://doi.org/10.1002/ajcp.12388

Comte, R. (2016). Neo-colonialism in music therapy: A critical interpretive synthesis of the literature concerning music therapy practice with refugees. Voices: A World Forum for Music Therapy, 16(3). https://doi.org/10.15845/voices.v16i3.865

Gonsalves, C. J. (1992). Psychological stages of the refugee provess: A model for therapeutic interventions. Professional Psychology: Research and Practice, 23(5), 382-389.

Guruge, S., \& Butt, H. (2015). A scoping review of mental health issues and concerns among immigrant and refugee youth in Canada: Looking back, moving forward. Canadian Journal of Public Health, 106(2). https://doi.org/10.17269/cjph.106.4588

Hadley, S., \& Norris, M. S. (2016). Musical multicultural competency in music therapy: The first step. Music Therapy Perspectives, 34(2), 129-137. https://doi.org/10.1093/mtp/miv045

Hassan, G., Ventevogel, P., Jefee-Bahloul, H., Barkil-Oteo, A., \& Kirmayer, L. J. (2016). Mental health and psychosocial wellbeing of Syrians affected by armed conflict. Epidemiology and Psychiatric Sciences, 25(02), 129-141. https://doi.org/10.1017/S2045796016000044

Hebebrand, J., Anagnostopoulos, D., Eliez, S., Linse, H., Pejovic-Milovancevic, M., \& Klasen, H. (2016). A first assessment of the needs of young refugees arriving in Europe: What mental health professionals need to know. European Child \& Adolescent Psychiatry, 25(1), 1-6. https://doi.org/10.1007/s00787-015-0807-0 
Koelsch, S. (2015). Music-evoked emotions: Principles, brain correlates, and implications for therapy: Functional neuroanatomy of music-evoked emotions. Annals of the New York Academy of Sciences, 1337(1), 193-201. https://doi.org/10.1111/nyas.12684

Laban, C. J., Gernaat, H. B. P. E., Komproe, I. H., Schreuders, B. A., \& De Jong, J. T. V. M. (2004). Impact of a long asylum procedure on the prevalence of psychiatric disorders in iraqi asylum seekers in the Netherlands. The Journal of Nervous and Mental Disease, 192(12), 843-851. https://doi.org/10.1097/01.nmd.0000146739.26187.15

Lauzon, G. (2019). The effectiveness of music therapy interventions with persons of concern: An integrative review. [Master's thesis, University of Kentucky]. https://uknowledge.uky.edu/ music_etds/144

Marquardt, L., Krämer, A., Fischer, F., \& Prüfer-Krämer, L. (2016). Health status and disease burden of unaccompanied asylum-seeking adolescents in Bielefeld, Germany: Cross-sectional pilot study. Tropical Medicine \& International Health, 21(2), 210-218. https://doi.org/ 10.1111/tmi.12649

McGregor, L. S., Melvin, G. A., \& Newman, L. K. (2015). Differential accounts of refugee and resettlement experiences in youth with high and low levels of posttraumatic stress disorder (PTSD) symptomatology: A mixed-methods investigation. American Journal of Orthopsychiatry, 85(4), 371-381. https://doi.org/10.1037/ort0000076

Mediendienst, I. (2020, June 12). Mediendienst Integration.https://mediendienst-integration.de/ migration/flucht-asyl/zahl-der-fluechtlinge.html

Metzner, F., Reher, C., Kindler, H., \& Pawils, S. (2016). Psychotherapeutische Versorgung von begleiteten und unbegleiteten minderjährigen Flüchtlingen und Asylbewerbern mit Traumafolgestörungen in Deutschland [Psychotherapeutic care of accompanied and unaccompanied underaged refugees and asylum seekers with secondary traumatic stress in Germany]. Bundesgesundheitsblatt - Gesundheitsforschung - Gesundheitsschutz, 59(5), 642-651. https://doi.org/10.1007/s00103-016-2340-9

Oral, R., Ramirez, M., Coohey, C., Nakada, S., Walz, A., Kuntz, A., Benoit, J., \& Peek-Asa, C. (2016). Adverse childhood experiences and trauma informed care: The future of health care. Pediatric Research, 79(1-2), 227-233. https://doi.org/10.1038/pr.2015.197

Orth, J. (2004). Sounds of trauma: Music therapy with traumatized refugees in a clinical Setting. In J. P. Wilson \& B. Drožðek (Eds.) Broken spirits: The treatment of asylum seekers and refugees with PTSD (pp. 443-480). Brunner-Routledge Press.

Orth, J. (2005). Music therapy with traumatized refugees in a clinical setting. Voices: A World Forum for Music Therapy, 5(2). https://doi.org/10.15845/voices.v5i2.227

Pelletier, C. L. (2004). The effect of music on decreasing arousal due to stress: A meta-analysis. Journal of Music Therapy, 41(3), 192-214.

Rolvsjord, R. (2015). Resource-oriented perspectives in music therapy. In J. Edwards (Ed.), The Oxford Handbook of Music Therapy. Oxford University Press. https://doi.org/10.1093/ oxfordhb/9780199639755.013.5

Scheiby, B. B. (2015). Analytical music therapy. In B. L. Wheeler (Ed.) Music therapy handbook (pp. 206-219). Guilford Press.

Stige, B. (2015). Community music therapy. In B. L. Wheeler (Ed.) Music therapy handbook (pp. 233-245). Guilford Press.

Sutton, J., \& De Backer, J. (2009). Music, trauma and silence: The state of the art. The Arts in Psychotherapy, 36(2), 75-83. https://doi.org/10.1016/j.aip.2009.01.009

Walworth, D. D. (2003). The effect of preferred music genre selection versus preferred song selection on experimentally induced anxiety levels. Journal of Music Therapy, 40(1), 2-14. https://doi.org/10.1093/jmt/40.1.2

Zharinova-Sanderson, O. (2004). Community music therapy with traumatised refugees in Berlin. In M. Pavlicevic \& G. Ansdell (Eds.), Community music therapy (pp. 233-248). Jessica Kingsley Publishers. 